\title{
A semente do incompreensível
}

\author{
Marco Belpoliti
}

1.

Em 1955, dez anos após o fim do segundo conflito mundial, Primo Levi escreve para um jornal turinense um breve texto sobre a memória do Lager, Deportados. Aniversário. A constatação é desoladora: em vez de se tornar história, o tema dos campos de extermínio encaminhou-se a um completo esquecimento. É um artigo amargo, mas escrito em seu tom habitual: comedido, preciso, enxuto. Não faz concessões à retórica, às lamentações, ao anátema. Contém considerações que antecipam em trinta anos as páginas de seu livro mais importante e ainda mal conhecido, I Sommersi e I Salvati, um dos textos capitais do século XX. Levi enfrenta muitos assuntos: a vergonha, a humanidade comum de vítimas e carrascos, a contaminação que ambos sofrem no Lager, a responsabilidade da cultura e da ciência européias no massacre nazista, a "morte inerte e nua, ignominiosa e imunda"; e trata também do testemunho dos sobreviventes, do possível fracasso histórico de seu testemunho perante os contemporâneos, da perda da memória (tudo pode ser repetido, inclusive o Lager). Mas propõe sobretudo reflexões sobre as "insuspeitadas reservas de ferocidade e loucura que jazem latentes no homem". Um tema que se tornou central nas sociedades de massa: a "zona cinzenta". No Lager não existem apenas os carrascos e as vítimas: entre o branco e o preto, entre o bem e o mal, há também uma vasta zona intermediária que abrange todos os que não são simplesmente carrascos ou vítimas, mas podem assumir ambas as posições alternadamente. Para poder funcionar, o Lager - mas não só o Lager - precisa da colaboração de muitos. Quanto mais o poder é opressivo, mais terá necessidade de colaboradores silenciosos; quanto mais estreito o círculo de poder, mais necessitará de auxiliares externos. Ao descrever a "zona cinzenta" e determinar o grau de responsabilidade direta e indireta dos indivíduos, Levi tem a clara noção de que o nosso patrimônio genético de animais gregários inclui uma inclinação precisa à dominação do homem sobre o homem. A história, inclusive a mais recente, continua infelizmente a confirmar a importância de tais considerações.

Quem escreve é o autor de Se Questo è un Uomo, um livro que é bem mais que um testemunho. Obra de clara inspiração literária - os seus modelos se encontram na tradição literária italiana e nos grandes escritores do século XIX -, o primeiro livro do jovem químico turinense, sobrevivente do campo de Monowitz, é também um livro de etologia humana. O Lager, como está escrito no capítulo de Se Questo è un Uomo, intitulado I Sommersi e I Salvati, foi "uma gigantesca experiência biológica e social". Desse valor experimental, do destino que caberia à Europa se as tropas de Hitler tivessem vencido a guerra, Levi volta a falar com insistência nos textos sobre Auschwitz que publica de modo mais ou menos esporádico nas duas décadas seguintes, seja em revistas de ex-deportados, seja nas páginas dos grandes diários nacionais. 
Antes de ser um judeu, Levi se sente alguém que combate pela liberdade, um resistente, e a ênfase recai não só no destino do seu povo, mas no de todos os homens e mulheres que foram deportados para a Alemanha, incluídas as centenas de milhares de soldados italianos que se recusaram a prestar juramento de lealdade à recém-nascida República de Salò, cuja história foi silenciada no pós-guerra. Mas também no resto da Europa, e até no Estado de Israel, se faz silêncio sobre os campos de extermínio, preferese o esquecimento, pelo menos desde o início dos anos 60 e do processo de Eichmann. O olhar que Levi lança nesses artigos sobre o fenômeno do extermínio dos judeus da Europa é tanto quanto possível distanciado, analítico, quase científico. O etólogo de Auschwitz busca primeiramente descrever o que ocorreu com o auxílio da razão, embora o problema da compreensão daqueles acontecimentos terríveis se demonstre imediatamente espinhoso: compreender significa entrar na cabeça de quem planificou e cometeu aqueles delitos que ultrapassam qualquer medida humana, isto é, como repete várias vezes o ex-deportado, justificar algo que está para além da própria razão humana.

O impasse é muito evidente: a estupidez e a desrazão, escreve Levi, são forças historicamente operantes, e no entanto os criadores de Auschwitz, afirma em 1968 na apresentação de uma obra (Prefaz̧ione a L. Poliakov, Auschwitz), não estão tomados por delírio ou ataque de fúria: "são diligentes, tranqüilos, vulgares e simples". Chega até a desejar que não nasça muito cedo um homem que seja capaz de comentar e tornar claro o porquê da inversão, no centro da nossa Europa e do nosso século, "do mandamento 'Não matarás"'. Obra de homens banais e ordinários, Auschwitz pertence evidentemente a uma assimetria, a algo que ao mesmo tempo é humano - continuam sendo homens aqueles que planejaram e executaram o imenso extermínio - e já não o é. Homens aparentemente comedidos, cinzentos, desbotados - vazios, idiotas, tranqüilos e diligentes, definiu-os em um texto de 1959 - foram capazes de cumprir atos que ultrapassam o entendimento humano (Monumento a Auschwita). Aqui há algo de inexplicável, além de inaceitável. A raiz racional do homem, postulada pelo pensamento grego, na qual se inspira o ex-aluno de liceu em suas reflexões antropológicas, é negada pela raiz, sem que no entanto esses mesmos homens, os assassinos de Auschwitz, estejam fora da espécie humana. A incompreensibilidade é várias vezes invocada nesses escritos. Há perguntas para as quais, de modo pacato, mas sutilmente angustiado, Levi não dá respostas. Perguntas que dizem respeito sobretudo ao extermínio (suas causas, a possibilidade de que fatos semelhantes se repitam): mas não só.

2.

Diante do suicídio coletivo da seita "Templo do povo", em 1978, e do suicídio solitário do filósofo Jean Améry, um ex-deportado como ele, autor de um livro importantíssimo, Intellettuale ad Auschwitz, Levi afirma que o suicídio é um ato incompreensível, se "compreender" significa ir à cata de motivos:

Toda ação humana contém um núcleo duro de incompreensibilidade: se não fosse assim, poderíamos prever o que o nosso próximo fará, coisa que não ocorre, e talvez seja bom que não ocorra. Particularmente difícil é penetrar o porquê de um suicídio, já que geralmente 
o próprio suicida não está consciente do seu ato ou fornece a si mesmo e aos outros motivações voluntária ou involuntariamente distorcidas.

Desde que Levi escreveu essas palavras se passaram vinte e quatro anos, mas tenho a impressão de que poucos, pouquíssimos, leram e meditaram sobre elas. A impressão é que, apesar de ser um dos autores mais lidos na Itália e no mundo, Levi ainda é pouco compreendido. É um destino curioso, que dá muito que pensar. Talvez seja por sua complexidade ou por sua natureza centáurica, como ele mesmo a definiu, mas talvez também por nossa pressa e às vezes até por nossa superficialidade de leitores. A importância de $S e$ Questo è un Uomo, como explicaram os estudiosos, não depende do testemunho dado pelo jovem químico de Turim, mas do seu valor literário. Basta comparar o primeiro livro de Levi com o de outros testemunhos do Lager e do campo de extermínio para perceber imediatamente a força expositiva, a clareza, a tessitura das frases. Em suma, Levi é um escritor - fato que por muito tempo não foi aceito ou compreendido (só poucos o fizeram: Franco Antonicelli, Arrigo Cajumi, Italo Calvino). É muito fácil dizer hoje, com o entendimento posterior, que era evidente, óbvio. Mas não foi assim. Até Natalia Ginzburg e Cesare Pavese, que devolveram ao remetente o manuscrito de Se Questo è un Uomo (ainda não se chamava assim), se enganaram. E até pelo menos 1975, talvez 1982, ano em que se publica Se non Ora Quando?, para a maioria da crítica literária italiana Primo Levi não era um escritor, mas uma espécie de diletante inspirado; ele mesmo se definia paradoxalmente como um escritor-não-escritor, porque tinha consciência do conflito que havia na própria obra entre testemunho e literatura (um conflito benéfico, mas que se adaptava mal a quem quis e quer ver nele apenas a testemunha).

Numa biografia decididamente ruim e imprecisa, Primo Levi o la Tragedia di un Ottimista, de Myriam Anissimov, afirmam-se coisas equivocadas sobre aquela recusa, sobre a qual o próprio Levi falou várias vezes em debates e entrevistas (reunidos em Primo Levi. Conversazioni e Interviste, Einaudi). A tese de que o editor Einaudi recusou Se Questo è un Uomo porque estava em curso uma remoção do extermínio judaico é falsa. Quem leu a obra com atenção sabe que Levi não escreveu um livro sobre o extermínio dos judeus da Europa (a palavra Holocausto era decididamente evitada pelo escritor), mas sobre o extermínio nazista em geral (judeus, deportados, militares, partisans, eslavos). Sobre esse ponto, basta ler o que o autor escreveu em jornais e revistas a partir dos anos 50 . O problema é que Levi é de fato um centauro, constituído de uma dupla natureza: escritor e testemunha, italiano e judeu, químico e escritor etc. Se Questo è un Uomo se inicia com uma declaração precisa: fui capturado como partisan, ameaçado de fuzilamento e mandado para o Lager como judeu. Levi sempre deu muita importância a esse aspecto de resistente, combatente pela liberdade, e o reiterou em vários textos. E esse é um outro aspecto de sua natureza bífida: escritor e cientista, testemunha e etólogo.

Por razões que seria interessante indagar, Levi tornou-se uma espécie de ícone do judeu deportado, um mártir vivo do Holocausto. Se ainda estivesse entre nós, com a tranqüilidade e o humor que o distinguiam, tomaria a devida distância dessa leitura parcial de si. Chegou a fazê-lo em alguns textos jornalísticos, seja quando põe muitas dúvidas acerca de sua identidade de escritor judeu, seja quando rechaça a santificação das vítimas do nazismo e reivindica o direito de indagar o que ocorreu, sobre o que não lhe parece 
fácil encontrar uma explicação. Primo Levi recusava a idéia de "compreender", se compreender for entrar na cabeça de quem projetou e planejou esses delitos além de qualquer medida humana. O que mais surpreende nele é justamente a ansiedade dessa pergunta: como cientista, como químico, buscava argumentos racionais diante de algo que não é racional, mas nem por isso é estranho à condição humana.

Para um homem de formação científica, dedicado a um ofício técnico, simultaneamente prático e teórico - o químico trabalha com as mãos, mas também com o cérebro, é um detetive da matéria -, constatar que existe um núcleo duro, impossível de explicar ou compreender (até em sentido moral), não é algo irrelevante. De resto, para o ex-deportado é evidente que na loucura de Auschwitz, no seu projeto disforme, há método e racionalidade. A insanidade não os exclui. Aliás, a aparência de modéstia e banalidade dos carrascos coaduna-se perfeitamente com a racionalidade anônima e cega das grandes instituições modernas. O próprio Höss, o pequeno-burguês comandante de Auschwitz, é a seu modo um inventor: resolveu o problema do extermínio inventando as câmaras de gás, nota Levi com ironia. Racionalidade e irracionalidade são opostas e simétricas; há entre as duas uma relação de igualdade, mesmo na oposição. Auschwitz é assimétrica em relação à razão, sua perfeita inversão, mas ao mesmo tempo em Auschwitz, no "anus mundi”, como o define em Sommersi e Salvati, a racionalidade impera: na organização do campo, na gestão dos prisioneiros, na eliminação sistemática dos "muçulmanos". Trata-se de um sistema coerente, conquanto invertido em relação à vida normal.

Agudo observador dos comportamentos humanos, das relações e dos sistemas de troca, o jovem químico turinense não se cansa de repeti-lo nas páginas de Se Questo è un Uomo. A hierarquia invertida do Lager é perfeitamente clara para ele, assim como a sua lógica. De tudo o que viu, ele extrai uma lição sobre a natureza humana; como moralista à Montaigne, observa a fronteira indefinida que separa não só a razão da desrazão, mas também o bem do mal. Ele vê com clareza - as páginas reunidas nesse volume o testemunham - a dupla raiz do comportamento humano. $\mathrm{Na}$ racionalidade, na própria civilização, já está contido o germe que pode gerar o seu oposto, o desencadeamento de forças irracionais e destrutivas. Não apenas como ato de cólera, do qual a guerra, como lhe ensinou Homero, é um prolongamento, mas também como ato frio e distanciado. A dissimetria da razão é algo de incalculável e imprevisível.

Em um longo colóquio, durante um ciclo de conferências turinenses mais tarde transcritas, Levi trata da questão do racismo ("A intolerância racial"). Estamos em 1979, em meio à crise política e social italiana, um ano depois do assassinato de Aldo Moro pelas Brigadas Vermelhas, temas também tratados por Levi. Após ter confessado com humildade a sua incompetência, o escritor assinala uma diferença radical entre os problemas etológicos e até biológicos do racismo e os problemas históricos e culturais. Como fiel leitor de Konrad Lorenz, detém-se no problema da agressividade intra-específica, no "chamado mal", de que ele constata não só a existência, mas também a ineliminável raiz biológica. Embora matizado por um certo determinismo, Levi não tem dúvidas quanto a isso: há uma intolerância racial pré-humana, pré-histórica, que precede e em parte justifica a intolerância histórica experimentada por seu povo - os judeus - de modo terrível e reiterado ao longo dos séculos. 
3.

$\mathrm{Na}$ raiz das perguntas sobre o porquê do mal e não do bem, o porquê do racismo e do inferno de Auschwitz, há mais uma vez uma questão de assimetria: a raiz do mal está no comportamento humano, na sua animalidade. A figura-chave de Se Questo è un Uomo é o animal-homem, o "Buck dos lobos" em modo transfigurado, a contrafigura do deportado: antes um tranqüilo cão doméstico, depois vítima inconsciente, finalmente Kapo da matilha de cães, "fera primitiva e dominadora". A analogia entre o protagonista de O Chamado da Selva, cuja tradução italiana de Gianni Celati Levi resenhou, e a vida do deportado, lançado da pacata casa burguesa para o inferno do Lager, é muito estreita: nos pontos extremos dos lugares concentracionários, em Auschwitz, o homem se encontra dramaticamente diante da própria irracionalidade, da qual não consegue desfazer-se, nem ontem, nem hoje. Ao descrever todo o arco das questões sobre a intolerância racial, na condição de não especialista, como se declara, o escritor segue o fio de um raciocínio fundado numa matriz racionalista, em um pessimismo da razão que, se não consegue curar as feridas que o homem infligiu ao próprio homem, surge como uma lúcida e impiedosa descrição do mal. Mas a sua reflexão deve ainda acertar contas com a dissimetria entre razão e não-razão, explicação e compreensão. E, como Levi é substancialmente um estóico, tanto no plano filosófico quanto no moral, a contradição não o assusta; provavelmente o faz sofrer, mas em nenhum momento ele abdica da própria racionalidade, que se apresenta, apesar de tudo, como um sólido baluarte contra a irrupção do irracional. O problema talvez seja outro.

Em um texto de sabor científico, publicado numa revista de divulgação e cultura em 1984, o ex-químico Primo Levi - que se aposentara dez anos antes para poder escrever - reflete sobre a relação entre assimetria e vida. É a retomada de um problema que ele enfrentara em sua tese de graduação, L'Inversione di Walden, que ele iniciara e depois, por causa das leis raciais, tivera que terminar de modo apressado e incompleto. Embora na forma de um extrato e sem a parte experimental, esse ensaio é de fato um condensado de sua tese, que o escritor redige depois de ter passado pela experiência assimétrica do Lager e de ter meditado longamente sobre isso entre si e com os outros. Em L'Asimmetria e la Vita, Levi expõe o problema que o interessou por tanto tempo: por que razão "os protagonistas do mundo vivente (as proteínas, as celuloses, os açúcares, o DNA) são todos assimétricos"? Como cientista, ele não pode deixar de constatar que a "assimetria esquerdadireita é intrínseca à vida. Coincide com a vida; está presente, inarredável, em todos os organismos, dos vírus aos líquenes, ao carvalho, ao peixe ao homem”.

O fato não é banal. Despertou a curiosidade de muitas gerações de cientistas. O tema, escreve ele, é o da "causa final" (Aristóteles) ou, "em termos modernos, o da utilidade adaptativa da assimetria". Levi repassa muitas de suas leituras, revê o problema tal como fora tratado durante a tese, à luz do que veio a conhecer da física e da química nos últimos vinte ou trinta anos; esboça cinco hipóteses para explicar a assimetria de que está tratando, chamada de "quiralidade", e chega a conjeturar o tema da antimatéria, a presença de um simétrico do ácido láctico direito ou da mão esquerda terrestre no "reino distante da antimatéria" (será que Levi, assim como Alice, passou por um breve período para o outro lado do espelho, entrando no reino assimétrico da morte?). Nas últimas linhas, ele fala da 
quiralidade do universo, ou apenas da nossa galáxia, como um fato perturbador, ao mesmo tempo dramático e enigmático.

A quiralidade é a condição segundo a qual uma molécula não pode ser superposta à sua imagem especular; indica, em outros termos, uma simetria não-simétrica, enantiomorfa, como a da mão direita e a mão esquerda, que são simétricas, mas invertidas, tanto que são superpostas por rotação, e não por translação, recorrendo a uma dimensão +1 em relação àquela em que se encontram. $\mathrm{O}$ tema das simetrias não-simétricas deve ter fascinado Levi a tal ponto que ele o retoma em várias ocasiões, particularmente em Chiave a Stella, dedicando-lhe muito do seu tempo e da sua inteligência. Por quê? Podemos pensar que não se trata apenas de um tema científico, mas que também está relacionado com a sua experiência no Lager, com aquela mistura de racionalidade e irracionalidade posta a dura prova em Auschwitz.

Acaso não é verdade que, no campo de extermínio, razão e não-razão são enantiomorfas? Que a racionalidade da vida normal é revirada pela lógica do campo, a qual, por sua vez, contém um princípio evidente de racionalidade intrínseca? Do mesmo modo, desde aquela experiência pareceu evidente ao cientista-Levi que a ciência ocidental continha um princípio de irracionalidade, a possibilidade sempre iminente de que suas potencialidades sejam utilizadas para fins destrutivos. Há um quiasma, um cruzamento, uma simetria cruzada entre racional e irracional. E isso, como seus contos fantásticos evidenciam, não diz respeito apenas ao lugar extremo e extraterritorial do Lager, mas também à vida cotidiana dos homens. O "vício de forma” é exatamente este. Nesse sentido devem ser interpretados os adjetivos com que Levi, ao final de L'Assimetria e la Vita, define a notícia da quiralidade do universo. Perturbadora, dramática, enigmática são os termos que se adaptam perfeitamente à descrição do evento incompreensível de Auschwitz. Contudo, a assimetria é também um fato vital, consubstancial à própria vida.

Conquanto existam substâncias assimétricas que não pertencem ao mundo vivo por exemplo, os cristais de quartzo -, a assimetria, escreve Levi, é "intrínseca à vida; coincide com a vida". Podemos cogitar que, para o químico turinense, escritor e ex-deportado, Auschwitz, mundo às avessas, enantiomorfo em relação à vida civil, seja parte da vida? Sim. A contradição insolúvel, eterna fonte de dor e de memória, é precisamente esta. E por mais de uma razão. Porque a experiência de Auschwitz é parte integrante da sua personalidade, da qual, como ele mesmo repete nessas páginas, recebeu o dom da escrita; e isso é fonte de alegria e de tormento. Além disso, o campo de Monowitz o fez compreender a raiz irracional do comportamento racional do homem, cuja viagem de volta ao mundo dos vivos, a sua Odisséia narrada em La Tregua, é a confirmação em traços ora cômicos e debochados, ora pesados e sombrios. O exame de química do doutor Pannwitz e a experiência do laboratório químico da Buna, de que dependeu sua salvação, esclareceramlhe no entanto o mau poder implícito na ciência e no seu uso. Em um nível mais profundo, na consciência atormentada e lucidíssima que aprendemos a conhecer nos seus livros, entendemos que o enantiomorfismo do Lager se sustenta sobre a dupla assimétrica dos "afogados" e dos "sobreviventes". Ele, Primo Levi, pertence à tropa dos segundos, e é uma testemunha justamente porque é um "sobrevivente". O quiasma é terrível de ser suportado.

Em seu último livro, I sommersi e i Salvati, ele escreve: 
A idéia de que este meu testemunho me tenha proporcionado o privilégio da sobrevivência, e de ter vivido por tantos anos sem grandes problemas, me inquieta, porque não vejo proporção entre o privilégio e o resultado.

Não é questão de sentimento de culpa. Como se percebe da leitura dos textos dedicados a Auschwitz e ao Lager, Levi não pretendeu esquecer ou viver ao abrigo de uma remoção mais ou menos bem-sucedida; ao contrário, ele se expôs ao papel de testemunha e enfrentou o problema de não querer esquecer; continua a escrever - mas nós passamos. Por isso ele continuou a bater contra a raiz quiral do seu talento de escritor. Por hábito mental, Levi não é um extremista. Mas é problemático, interroga-se continuamente, o que não o impede de tomar posições firmes, duras e inequívocas sobre o fascismo, o nazismo, o negacionismo de Robert Faurisson, o revisionismo histórico - Buraco Negro de Auschwitz. ainda é um artigo de grande atualidade -, a União Soviética.

Em Se Questo è un Uomo há um ponto preciso em que emerge esse aspecto de sua personalidade humana e intelectual. Está no capítulo Iniz̨iažione, que o escritor acrescentou dez anos após a publicação do livro, em 1958, quando saiu a segunda edição revista e atualizada pela Einaudi. Nele aparece a figura emblemática de Steinlauf, que fora sargento do exército austro-húngaro e cruz-de-ferro da guerra de 1914-18. Na condição de militar caído no poço sem fundo do Lager, Steinlauf ensina ao prisioneiro judeu italiano a dura lei do Campo:

Como o Lager é uma grande máquina para nos reduzir a feras, não devemos nos tornar feras; porque mesmo neste lugar é possível sobreviver, e para isso é preciso querer sobreviver, para poder levar o testemunho. Mas para viver é preciso salvar pelo menos o esqueleto, o arcabouço, a forma da civilização.

O sargento austríaco fornece uma série de indicações práticas ao seu aluno: lavar o rosto sem sabão, polir os sapatos, caminhar ereto. Trata-se de um paradoxo, um dos tantos paradoxos impostos pelo Lager. Opor ao informe do Lager a forma da vida civil; pois a formalidade dos comportamentos é tão importante quanto a luta sem trégua por um pedaço de pão, assim como aquele personagem de Lilith, que mantém sua dignidade evitando coçar em publico a sarna que o aflige. As estratégias de sobrevivência subvertem a relação habitual entre o que é lógico e o que é ilógico, ou entre o racional e o irracional. Mas não é certo que seja esse o raciocínio do judeu italiano Primo Levi.

Mais uma vez ele nos reserva uma surpresa. As palavras de Steinlauf não lhe bastam, e não só pelo costume italiano de mitigar tudo, de tornar maleável e branda toda doutrina, como ele diz, mas porque a sabedoria e a virtude do ex-militar não lhe são suficientes: "Diante desse complicado submundo, minhas idéias estão confusas; será mesmo necessário elaborar um sistema e praticá-lo, ou não será mais saudável ter consciência de que não há um sistema?”. A grandeza de Primo Levi não reside, como se vê nesses breves escritos, na denúncia ou no testemunho - embora também este aí -, mas na obstinação por colocar perguntas que não têm respostas certas ou que, se têm, põem em crise as opiniões assentadas, tanto de indivíduos quanto de grupos humanos. O que se colhe sob a prosa marmórea de Levi é um novelo, que se estende sob o tom razoável e calmo com que pronuncia todas as ações de acusação contra os falsários de ofício, os hipócritas, os contraventores (Cercatori di 
menzogne per negare l'olocausto), contra os que usam o evento terrível de Auschwitz para despachar falsas verdades ou vender coisas mórbidas a bom preço (Film e svastiche), a mesma atitude quando examina o evento midiático de Holocausto (Le immagini di Olocausto), ou quando mostra o otimismo excessivo da ciência moderna (Vediamo un po' quali cose si sono avverate e Cosa è bruciato nello spaz̧io), ou quando toca no problema do fim das ideologias:

Hoje muitas lágrimas se derramam pelo fim das ideologias; parece-me que este livro demonstra de modo exemplar o que pode causar uma ideologia que seja aceita com a radicalidade dos alemães de Hitler, e dos extremistas em geral. As ideologias podem ser boas ou ruins; é bom conhecê-las, compará-las e tentar avaliá-las; é sempre um mal desposar apenas uma, ainda que imantada por palavras respeitáveis como Pátria e Dever. ${ }^{2}$

Toda a obra de Primo Levi, a da testemunha e a do escritor, a do químico e a do narrador, se inscreve sob o signo da quiralidade, de uma simetria não-simétrica, que tenta conferir razão, com dificuldade, mas com grande inteligência e honestidade, ao evento perturbador, ao mesmo tempo dramático e enigmático, que foi Auschwitz. A impossibilidade de esquecer não decorre tanto, ou apenas, da medida desmedida dessa tragédia, mas do enredamento de questões difíceis de desatar e que, desde então até hoje, se reapresentaram na história dolorosa da humanidade, no Camboja e em Cuba, em Uganda e no Afeganistão. Por isso as palavras de Primo Levi nos são ainda indispensáveis.

\section{Notas}

1 J. Améry, Intellettuale ad Auschwitz,Torino, Bollati Boringhieri, 1987.

2 Ref. a Prefazione a Rudolf Höss, Comandante ad Auschwitr: 